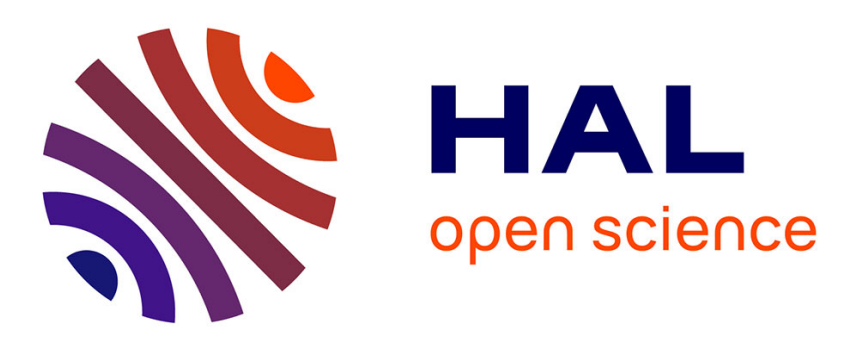

\title{
Thermomechanical loading applied on the cladding tube during the pellet cladding mechanical interaction phase of a rapid reactivity initiated accident
}

Arthur Hellouin de Menibus, Jérôme Sercombe, Quentin Auzoux, Christophe Poussard

\section{To cite this version:}

Arthur Hellouin de Menibus, Jérôme Sercombe, Quentin Auzoux, Christophe Poussard. Thermomechanical loading applied on the cladding tube during the pellet cladding mechanical interaction phase of a rapid reactivity initiated accident. Journal of Nuclear Materials, 2014, 453, pp.210-213. 10.1016/j.jnucmat.2014.06.046 . hal-01057281

\section{HAL Id: hal-01057281 https://hal.science/hal-01057281}

Submitted on 22 Aug 2014

HAL is a multi-disciplinary open access archive for the deposit and dissemination of scientific research documents, whether they are published or not. The documents may come from teaching and research institutions in France or abroad, or from public or private research centers.
L'archive ouverte pluridisciplinaire HAL, est destinée au dépôt et à la diffusion de documents scientifiques de niveau recherche, publiés ou non, émanant des établissements d'enseignement et de recherche français ou étrangers, des laboratoires publics ou privés. 


\title{
Thermomechanical Loading Applied on the Cladding Tube During the Pellet Cladding Mechanical Interaction Phase of a Rapid Reactivity Initiated Accident
}

\author{
Arthur Hellouin de Menibus*1, Jerome Sercombe ${ }^{2}$, Quentin \\ Auzoux $^{3}$, and Christophe Poussard ${ }^{3}$ \\ ${ }^{1}$ CEA Saclay/DEN/DANS/DMN/SRMA, 91191 Gif-sur-Yvette, France \\ ${ }^{2}$ CEA Cadarache/DEN/CAD/DEC/SESC, 13108 St Paul lez Durance, France \\ ${ }^{3} \mathrm{CEA}$ Saclay/DEN/DANS/DMN/SEMI, 91191 Gif-sur-Yvette, France
}

Published in 2014 in the Journal of Nuclear Materials

Volume 453, Issues 13, October 2014, Pages 210 to 213

http://www.sciencedirect.com/science/article/pii/S0022311514004036

\begin{abstract}
Calculations of the CABRI REP-Na5 pulse were performed with the ALCYONE code in order to determine the evolution of the thermomechanical loading applied on the cladding tube during the PelletCladding Mechanical Interaction (PCMI) phase of a rapid Reactivity Initiated Accident (RIA) initiated at $280^{\circ} \mathrm{C}$ that lasted $8.8 \mathrm{~ms}$. The evolution of the following parameters are reported : the cladding temperature, heating rate, strain rate and loading biaxiality. The impact of these parameters on the cladding mechanical behavior and fracture are then briefly reviewed.
\end{abstract}

Keywords: Zirconium, Cladding Tube, Reactivity Initiated Accident (RIA)

*Tel.: +33 1690839 43; e-mail: arthur.hellouin-de-menibus@cea.fr 


\section{Introduction}

The most critical postulated RIA scenario in a nuclear pressurized water reactor is a control rod ejection (REA : Rod Ejection Accident) that induces a large energy deposition in the surrounding fuel pellets [1]. As a consequence, the pellets from the surrounding fuel rods expand suddenly, which induces deformation and heating of the cladding tubes. The approach followed internationally to study the cladding tubes resistance to fracture in RIA conditions, to in fine improve the accuracy of the associated safety criteria, is divided into three complementary parts:

1. Integral tests performed on one instrumented fuel rod at a time in nuclear research reactors;

2. Dedicated multi-physical codes, which model the pellet and/or cladding tube behaviour during the RIA transient. These codes allowed for instance to identify the thermomechanical loading applied on the cladding tube;

3. In-laboratory tests and associated numerical simulations to study separately, or in a partially coupled way, the effect of different parameters on the pellet and cladding tube behaviour. Focusing on the mechanical behaviour of cladding tubes, such parameters are for instance the temperature level, the strain rate, the stress state, the characteristics of the contact between pellet and cladding tube and the loading mode (displacement or load controlled), the irradiation level, the hydrogen and hydrides concentration and distribution, etc.

The RIA chronological scenario were described in numerous reports [1,2]. The generally reported thermomechanical loading for the Pellet Cladding Mechanical Interaction (PCMI) phase are the following. The strain rate is on the order of $1 / \mathrm{s}[1]$. The cladding temperature depends on the pulse characteristics, but it typically reaches $600-800{ }^{\circ} \mathrm{C}$ at fracture on the inner side and about $300^{\circ} \mathrm{C}$ on the outer side when the initial coolant temperature is $286{ }^{\circ} \mathrm{C}$ [3]. The cladding tube heating rate is about $10^{4} \mathrm{~K} / \mathrm{s}$ [1]. The loading triaxiality level is included between plane-strain $\left(\varepsilon_{z z}=0\right)$ and equibiaxial $\left(\varepsilon_{\theta \theta}=\varepsilon_{z z}\right)$ conditions [4]. Nevertheless, data on the evolution of the loading applied on the cladding tube during the PCMI phase starting from PWR working temperature are scarce in the open litterature. 
Thus, CABRI REP-Na5 calculations with the ALCYONE code developed at the CEA $[5,6]$ were performed in the present study to evaluate the evolution of the thermomechanical loading during the PCMI phase. A material anisotropic plastic behaviour law for the cladding tube that was specifically identified in RIA-PCMI conditions by Le Saux et al. [7] was used.

First ALCYONE code and procedures are described, together with the CABRI REP-Na5 characteristics. Then, the evolution of the thermomechanical loading on the cladding is exposed in terms of temperature, heating rate, strain rate and loading biaxiality and are compared with the generally reported range for these parameters. The impact of these parameters on the cladding mechanical behavior and fracture are then reviewed.

\section{ALCYONE code and procedures}

ALCYONE is a multi-dimensional code used to study the behaviour of PWR fuel rods during normal, off-normal and accidental conditions [5, 6]. ALCYONE output results from the 1.5D fuel rod scheme for the CABRI REP-Na5 pulse [8] were used in the present study to determine the evolution of the thermomechanical loading on the cladding tube in RIA PCMI phase. This integral test was done on a $64 \mathrm{GWd} / \mathrm{tU}$ irradiated Zircaloy-4- $\mathrm{UO}_{2}$ rod with a maximum oxide thickness of $25 \mu \mathrm{m}$. The peak mid-height width was 8.8 $\mathrm{ms}$ and the enthalpy was $104 \mathrm{cal} / \mathrm{g}$. The tests were performed in a sodium coolant at an initial temperature of $280^{\circ} \mathrm{C}$. ALCYONE calculations of the REP-Na tests led to results in very good agreement with the measured posttest axial profilometry, clad and fuel elongations [5] (figure 1(a) shows the calculated and measured clad diameter before and after the REP-Na5 pulse test). Since this first publication of this work, the modelling of the heat and mass transport in the sodium coolant has been improved by a description of the heat exchanges between the coolant and the outer Niobium ring of the CABRI experimental rig. The instrumentation device of the REP-Na tests included thermocouples placed at several axial and azimuthal locations which were be used to assess the quality of the heat radial and axial transfer in the fuel pellet - cladding - coolant system. The coolant variations of temperature during the REP-Na5 are extremely well reproduced by ALCYONE (figure 1(b)) with the assumption of a very high conductance at the pellet-clad interface. This assumption already stressed in SCANAIR calculations of the REP-Na tests [9] is of great importance with respect to the evaluation of the 
thermal gradient in the cladding. In ALCYONE 1.5D model, the REP-Na5 refabricated rod is simulated with 10 axial slices of equal height. All the results presented in the next parts are relative to the slice situated at the maximum Linear Heat Rate (LHR).

\section{Results and analysis : thermomechanical loading on the cladding tube during the PCMI phase}

\section{$3.1 \quad$ Temperature}

In a time interval right after the pulse maximum where various rod fracture were observed [3], the cladding inner surface temperature is between $700{ }^{\circ} \mathrm{C}$ and $800{ }^{\circ} \mathrm{C}$. At this time, it is about $300{ }^{\circ} \mathrm{C}$ on the outer surface (figure $2(\mathrm{a})$ ). These temperatures are similar to the ones calculated with the RANNS code for the Va-3 pulse in NSRR (4.4 ms and $82 \mathrm{cal} / \mathrm{g}$ peak - Sugiyama et al. [3]). The results of Sugiyama et al. [3] showed that for the same peak enthalpy, a 3 times longer peak does not affect much the minimum and maximum temperatures. Neverthless, it induced a smoother temperature distribution in the cladding thickness for longer pulses. The thermal gradient in the cladding tube thickness reduces the tensile circumferential stress on the inner diameter and increases the one on the outer diameter. In addition, as the elasticity modulus and the yield stress decrease when the temperature increases, the stress levels for a given strain are smaller on the inner diameter than on the outer one. Both effects induce higher stress levels on the outer surface than on the inner one (figure 2(b)). Sugiyama et al. [3] results indicated that $60 \%$ and $85 \%$ of the cladding section was at a temperature lower than $350{ }^{\circ} \mathrm{C}$ and $480^{\circ} \mathrm{C}$ respectively at cladding fracture. In laboratory tests that aimed at studying RIA conditions should therefore take into account the temperature level as it affects the material mechanical and thermal behaviour [7] and the fracture process $[10,11,12]$, the quantity of dissolved hydrides [13] and the extent of the irradiation recovery [14]. The temperature gradient in the cladding wall is likely one of the thermomechanical loading conditions that is most difficult to reproduce experimentally. This aspect may nevertheless be adressed by computational analyses, such as those of the present study, by using a material behaviour law identified in isothermal conditions covering 


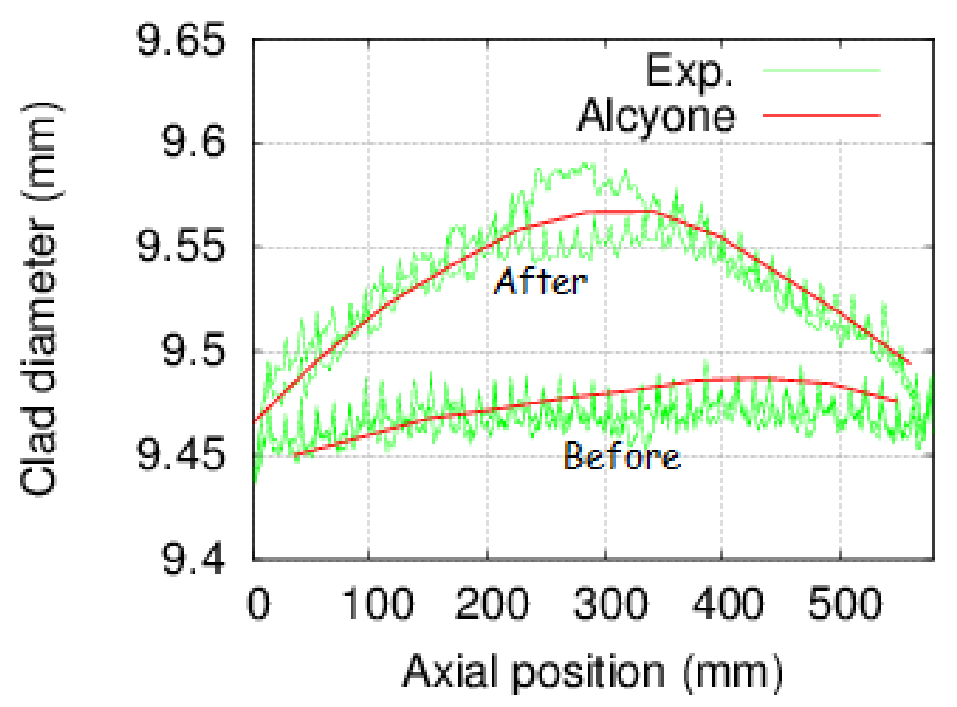

(a)

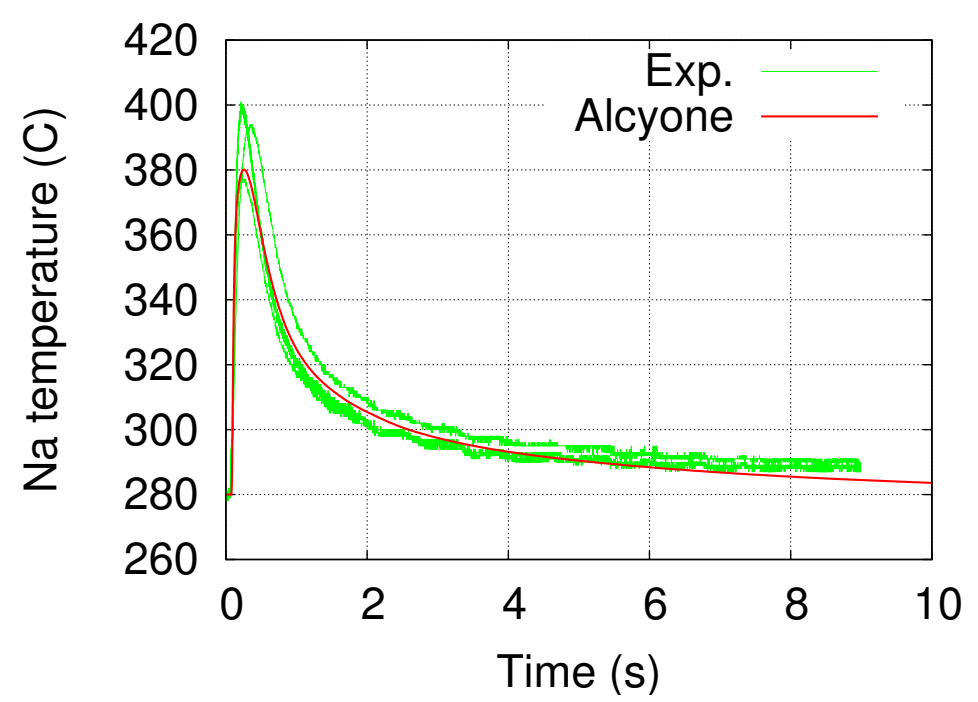

(b)

Figure 1: Calculated and measured clad diameters and sodium temperatures for the CABRI REP-Na5 pulse: (a) clad diameter before and after the pulse and (b) sodium temperature during the pulse at the position of the maximum Linear Heat Rate. 
the PCMI phase representative temperature range.

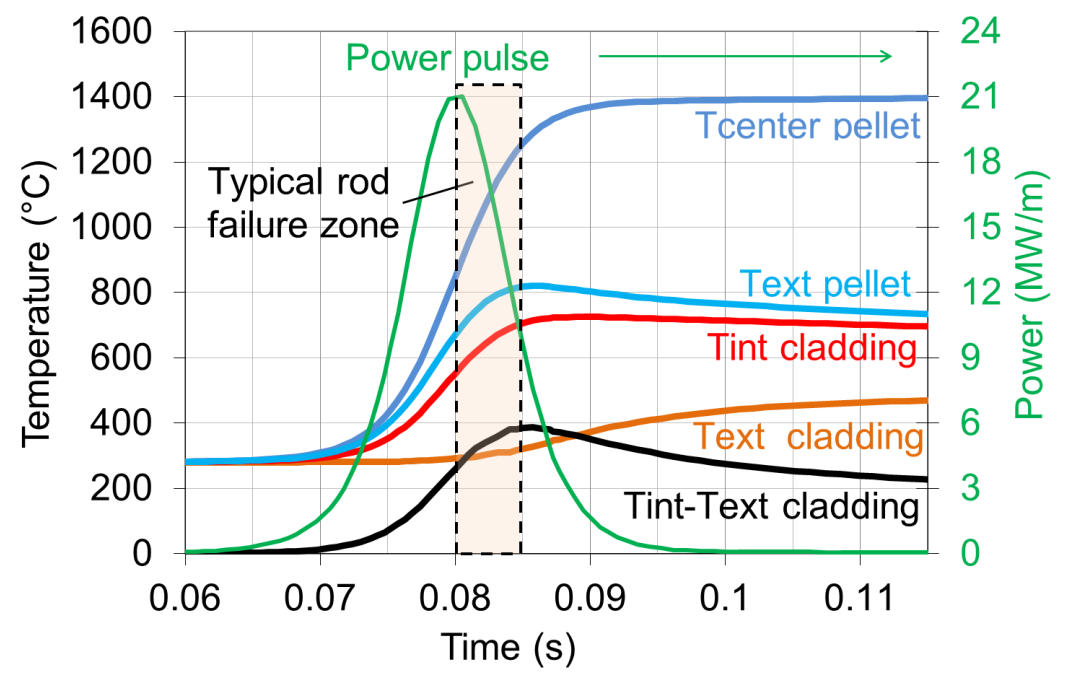

(a)

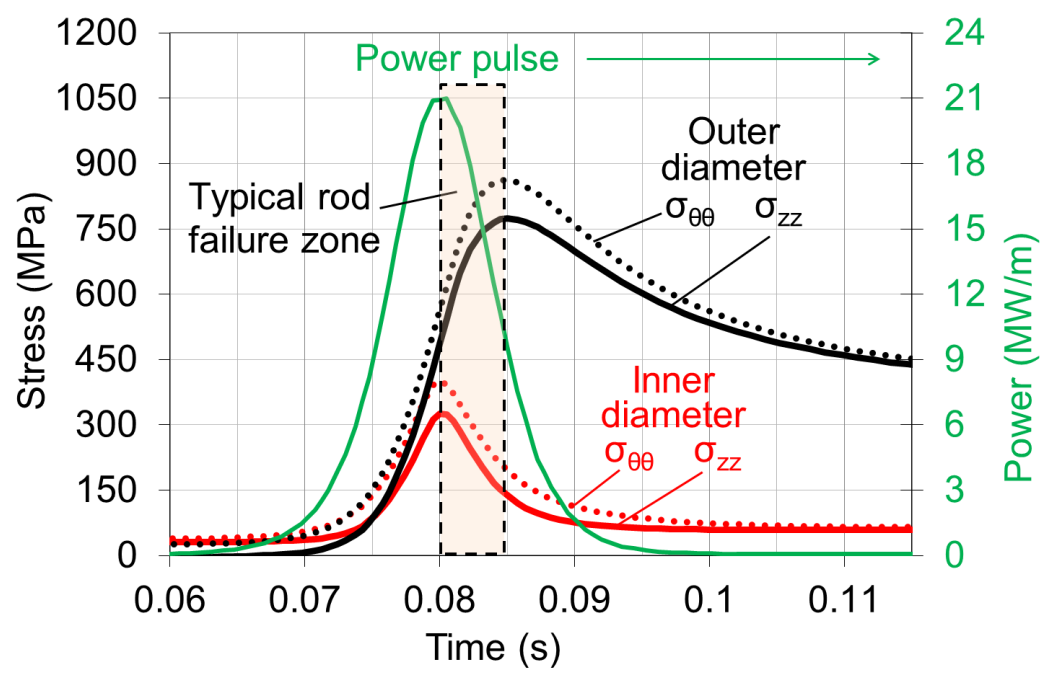

(b)

Figure 2: ALCYONE outputs for the CABRI REP-Na5 pulse: (a) cladding temperature and (b) stress levels. 


\subsubsection{Heating rate}

The maximum heating rate calculated by ALCYONE is $10^{4}{ }^{\circ} \mathrm{C} / \mathrm{s}$ on the outer surface, in good agreement with NEA [1] data, but is 5 times higher on the inner surface (figure 3(a)). To the authors knowledge, no work is available on the irradiation recovery or the dislocation recovery and the material recrystallisation at such high heating rate. Recent results obtained at $350{ }^{\circ} \mathrm{C}$ and high heating rate (about $2-5 \times 10^{3}{ }^{\circ} \mathrm{C} / \mathrm{s}$ ) indicated that the hydride dissolution might be fast enough so that the high heating rate, measured by infrared pyrometry techniques, does not affect the hydrogen partition into hydrogen and hydrides at a given temperature [15]. This result is in contradiction with Kearns [13] results. He estimated the complete dissolution of 100-200ppm hydrided samples at $350^{\circ} \mathrm{C}$ was higher than 10 seconds, which is 100 times longer than the experiments carried out in [15]. The results

reported by Yueh et al. [15] might be explained by the limited influence of 100-130ppm of hydrides at $350^{\circ} \mathrm{C}$ [10] ( $100 \mathrm{ppm}$ is the quantity dissolved at $350^{\circ} \mathrm{C}$ at low heating rates).

\subsection{Circumferential strain rate}

The circumferential strain rate calculated by ALCYONE is between $0.9 / \mathrm{s}$ and $1.3 / \mathrm{s}$ (figure $3(\mathrm{~b})$ ). This is in agreement with the $1 / \mathrm{s}$ strain rate indicated by the NEA [1]. Longer pulses leads to lower circumferential strain rates, for example $0.15 / \mathrm{s}$ in the $76 \mathrm{~ms}$ mid-width duration REP-Na4 pulse [1]. It is important to consider RIA representative strain rates in experiments aiming at studying the cladding fracture in the PCMI phase. Indeed, it was shown that strain rates higher than $0.1 / \mathrm{s}$ can induce material heating due to plastic dissipation [16]. More precisely, average temperature increases $\left(10-15^{\circ} \mathrm{C}\right)$ were measured in the range $0.1-1 / \mathrm{s}$, but not strongly localized due to temperature homogenization by thermal conduction, while high and strongly localized temperature increases (more than $100^{\circ} \mathrm{C}$ ) were measured in the range 1-10/s [16]. Local heating could enhance strain localization, which itself would reinforce the temperature localization and so on.

\subsection{Loading biaxiality}

The mechanical loading is mainly due to fuel pellet expansion, which induce a ratio of the plastic axial strain divided by the plastic circumferential strain 


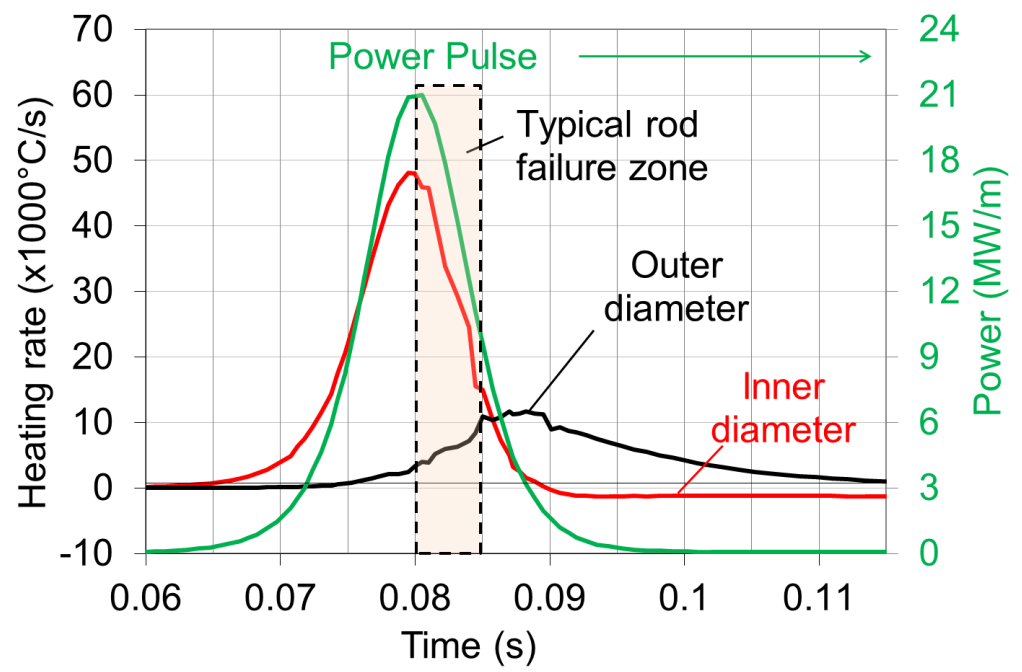

(a)

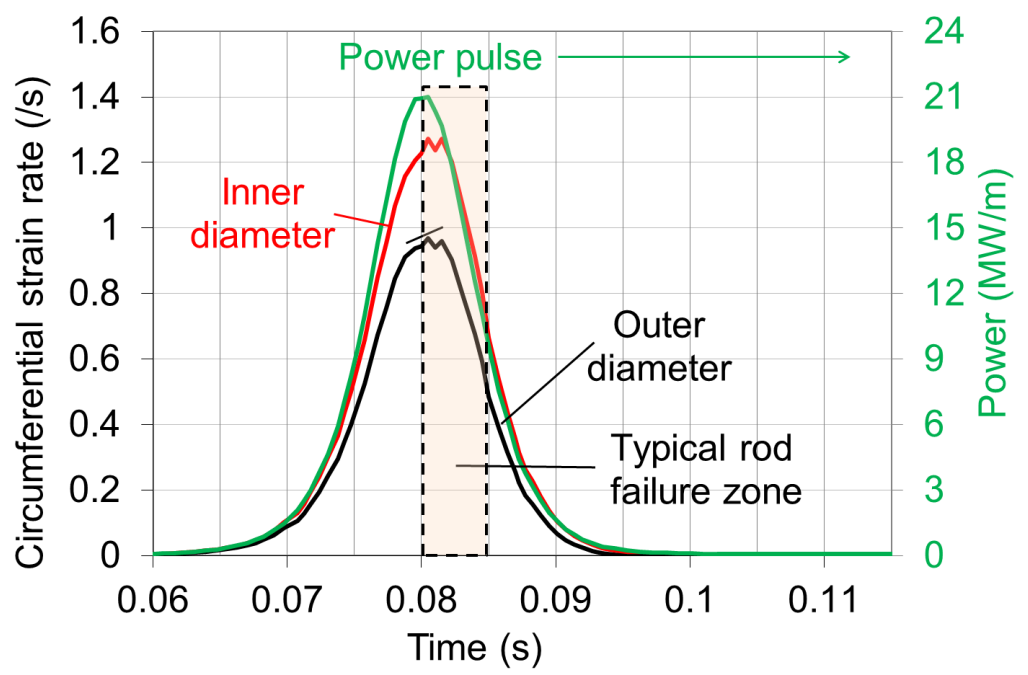

(b)

Figure 3: ALCYONE outputs for the CABRI REP-Na5 pulse: (a) heating rate and (b) circumferential strain rate. 
$\varepsilon_{z z}^{p} / \varepsilon_{\theta \theta}^{p}$ between 0.2 and 0.7 in CABRI REP Na tests based on postmortem measurements (Cazalis et al. [4]). The associated ratio of the axial stress on the circumferential stress $\sigma_{z z} / \sigma_{\theta \theta}$ depends on the material anisotropy. The equivalent stress $\left(\sigma_{e q}\right)$ using the Hill plasticity criterion and neglecting the shear terms is :

$$
\sigma_{e q}^{2}=H_{r r}\left(\sigma_{\theta \theta}-\sigma_{z z}\right)^{2}+H_{\theta \theta}\left(\sigma_{z z}-\sigma_{r r}\right)^{2}+H_{z z}\left(\sigma_{r r}-\sigma_{\theta \theta}\right)^{2}
$$

Using this potential for the material constitutive equation :

$$
\dot{\varepsilon}^{p}=\dot{\lambda} \frac{\partial \sigma_{e q}}{\partial \bar{\sigma}}
$$

it results in :

$$
\frac{\varepsilon_{z z}^{p}}{\varepsilon_{\theta \theta}^{p}}=\frac{\left(H_{r r}+H_{\theta \theta}\right) \frac{\sigma_{z z}}{\sigma_{\theta \theta}}-H_{r r}}{H_{r r}+H_{z z}-H_{r r} \frac{\sigma_{z z}}{\sigma_{\theta \theta}}}
$$

The CWSR Zircaloy-4 anisotropy coefficients were identified in the mechanical behaviour model developed by Le Saux et al. [7] :

$$
\left\{\begin{array}{l}
H_{r r}=0,485+\frac{0,095 \times(1-\Phi)}{1+\exp (12(T / 740-1))}+\frac{0.32 \Phi}{1+\exp (10(T / 660-1))} \\
H_{\theta \theta}=1-H_{r r} \\
H_{z z}=0,52+\frac{\left(4 \times 10^{-4}-0,23\right)(1-\Phi)}{1+\exp (15(T / 550-1))}-\frac{0.16 \Phi}{1+\exp (20(T / 920-1))}
\end{array}\right.
$$

with $T$ the temperature in kelvin and $\Phi$ is a neutron fluence $(\phi)$ dependent variable, in $10^{25} \mathrm{n} / \mathrm{m}^{2}$ :

$$
\Phi=(1-0.3 \phi)
$$

Thus, the relationship between the strain and stress ratio depends on both the temperature and the irradiation level (figure 4(a)). In the REPNa5 pulse, ALCYONE estimates that the stress ratio is between 0.6 and 0.95 (figure 4(b)), in agreement with the measured and theoretically predicted values (figure 4(a)). Representative loading biaxialities should be taken into account as the detrimental effect of a high biaxiality level mechanical loading on the ductile fracture is well known [17]. Concerning zirconium alloys, this effect was confirmed on unirradiated recrystallized Zircaloy-2 sheets [18], on unirradiated recrystallized Zircaloy-2 tubes [19], on unirradiated recrystallized Zircaloy-4 [20], on unirradiated and irradiated Zr-1\%Nb tubes [21] and on unirradiated CWSR Zircaloy-4 by means of EDC and HB-EDC tests [22]. 


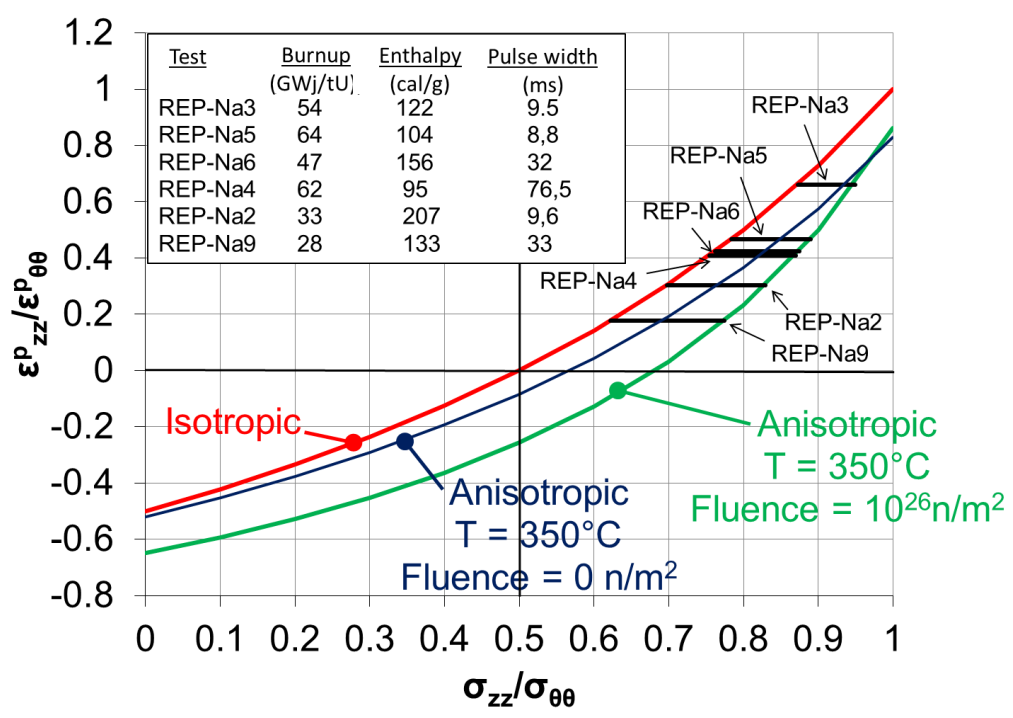

(a)

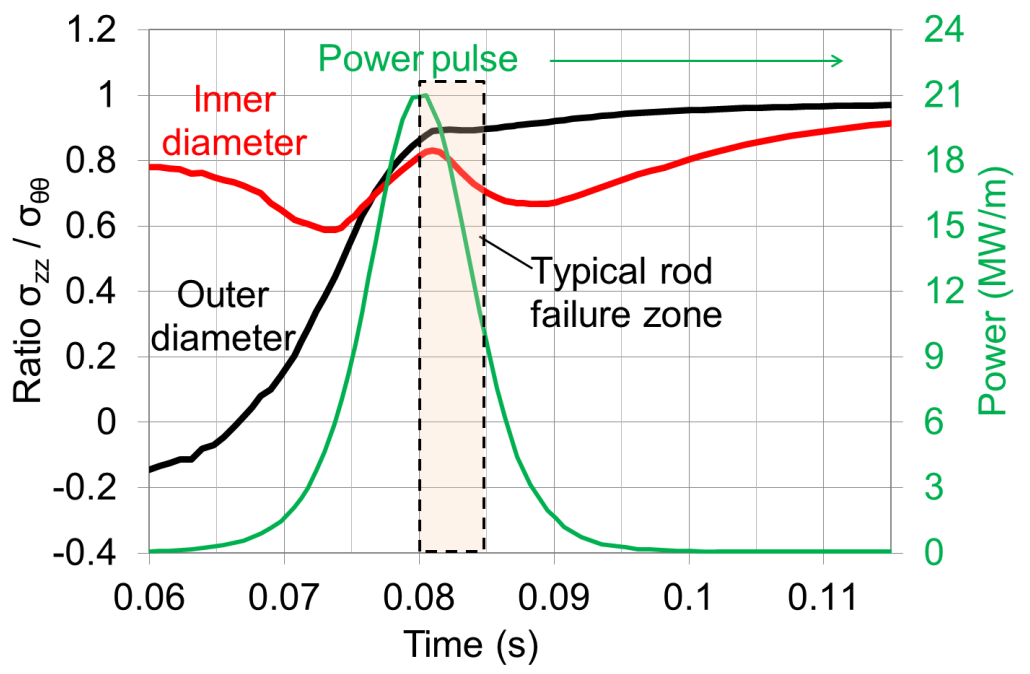

(b)

Figure 4: Figure (a) represents the strain biaxiality ratio obtained from external diameter and total rod axial elongation measurements after integral tests versus the stress biaxiality ratio, which depends on the material anisotropy. Figure (b) represents the stress biaxiality ratio estimated by ALCYONE for CABRI REP-Na5. 


\section{Conclusion}

ALCYONE calculations of CABRI REP-Na5 pulse were performed to evaluate the evolution of the thermo-mechanical loading on the cladding tube during the whole transient of a rapid RIA transient ( $8.8 \mathrm{~ms}$ pulse width). The results can be summarized as follow :

- The temperature rise quickly up to $700-800{ }^{\circ} \mathrm{C}$ on the inner diameter, while it remains about $300^{\circ} \mathrm{C}$ on the external diameter. This temperature range is covered by some already published material data and constitutive equations [7] and the thermal gradient aspect is taken into account in numerical simulations such as the one described in the present paper.

- The heating rate is about $10^{4} \mathrm{C} / \mathrm{s}$ on the outer diameter but is about 5 times higher on the inner diameter. Additional work is required to quantify the impact on the evolution of the material microstructure and properties of such a high strain rate.

- The circumferential strain rate is between 0.9 and $1.3 / \mathrm{s}$. Additional work is required to evaluate the impact of the local heating due to plastic dissipation on the material fracture in this intermediate strain rate range where adiabatic assumption are not valid [16].

- The stress biaxiality is between 0.6 and 0.95. Efforts are currently underway to develop easy-to-use testing techniques on cladding tubes that cover such loading biaxiality levels [22, 12, 23].

\section{Bibliography}

\section{References}

[1] NEA, Nuclear fuel behaviour under reactivity-initiated accident (RIA) conditions, OECD, 2010.

[2] T. Fuketa, T. Sugiyama, Current RIA-related regulatory criteria in Japan and their technical basis, in: Workshop RIA, Paris, France, 2009. 
[3] T. Sugiyama, Y. Udagawa, M. Suzuki, F. Nagase, Influence of coolant temperature and power pulse width on fuel failure limit under reactivityinitiated accident conditions, in: International Topical Meeting on Light Water Reactor Fuel Performance, Chengdu, China, 2011.

[4] B. Cazalis, J. Desquines, C. Poussard, M. Petit, Y. Monerie, C. Bernaudat, P. Yvon, X. Averty, The PROMETRA program: Fuel cladding mechanical behavior under high strain rate, Nuclear Technology 157 (2007) 215-229.

[5] J. Sercombe, E. Federici, M. Le Saux, B. Michel, C. Poussard, 1D and 3D Modeling of PCMI during a RIA with ALCYONE V1.1, in: International Topical Meeting on Light Water Reactor Fuel Performance, Orlando, Florida, 2010.

[6] J. Sercombe, I. Aubrun, C. Nonon, Power ramped cladding stresses and strains in 3D simulations with burnup-dependent pellet-clad friction, Nuclear Engineering and Design 242 (2012) 164-181.

[7] M. Le Saux, J. Besson, S. Carassou, C. Poussard, X. Averty, A model to describe the anisotropic viscoplastic mechanical behavior of fresh and irradiated Zircaloy-4 fuel claddings under RIA loading conditions, Journal of Nuclear Materials 378 (2008) 60-69.

[8] J. Papin, B. Cazalis, J. Frizonnet, E. Federici, F. Lemoine, Synthesis of CABRI-RIA tests interpretation, in: Eurosafe Meeting, Paris, France, 2003.

[9] J. Papin, B. Cazalis, J. Frizonnet, J. Desquines, F. Lemoine, V. Georgenthum, F. Lamare, M. Petit, Summary and interpretation of the CABRI REP-Na program, Nuclear Technology 157 (3) (2007) 230-250.

[10] M. Le Saux, J. Besson, S. Carassou, C. Poussard, X. Averty, Behavior and failure of uniformly hydrided Zircaloy- 4 fuel claddings between 25 and $480^{\circ} \mathrm{C}$ under various stress states, including RIA loading conditions, Engineering Failure Analysis 17 (2010) 683-700.

[11] A. Hellouin de Menibus, Formation de blisters d'hydrures et effet sur la rupture de gaines en Zircaloy-4 en conditions d'accident d'injection de reactivite, Ph. d. thesis, Mines Paristech, Centre des Materiaux (2012). 
[12] A. Hellouin de Menibus, Q. Auzoux, P. Mongabure, V. Macdonald, T. Le Jolu, J. Besson, J. Crepin, Fracture of Zircaloy-4 Cladding Tubes with or without Hydride Blisters in Uniaxial to Plane Strain Conditions with Standard and Optimized Expansion Due to Compression Tests, Materials Science and Engineering: A 604 (2014) 57-66.

[13] J. Kearns, Dissolution kinetics of hydride platelets in Zircaloy-4, Journal of Nuclear Materials 27 (1968) 64-72.

[14] J. Ribis, F. Onimus, J. Bechade, S. Doriot, C. Cappelaere, C. Lemaignan, A. Barbu, O. Rabouille, Experimental and modeling approach of irradiation defects recovey in zirconium alloys : impact of an applied stress, Journal of ASTM International 5 (3) (2008) 1-21.

[15] K. Yueh, V. Grigoriev, Y. Lin, D. Lutz, D. Schrire, Zircaloy-2 ductility recovery under RIA transient conditions, in: International Topical Meeting on Light Water Reactor Fuel Performance, Chengdu, China, 2011.

[16] A. Hellouin de Menibus, Q. Auzoux, J. Besson, J. Crepin, Temperature Increase of Zircaloy-4 Cladding Tubes due to Plastic Heat Dissipation During Tensile Tests at Reactivity Initiated Accident Representative Strain Rates, in: Light Water Reactor Fuel Performance Meeting, American Nuclear Society, Charlotte, North Carolina, USA, 2013.

[17] J. Rice, D. Tracey, On the Ductile Enlargement of Voids in Triaxial Stress Fields, Journal of the Mechanics and Physics of Solids 17 (1969) 201-217.

[18] F. Yunchang, D. Koss, The influence of multiaxial states of stress on the hydrogen embrittlement of zirconium alloy sheet, Metallurgical Transactions A 16 (1985) 675-681.

[19] H. Maki, M. Ooyama, Plastic deformation and fracture behavior of Zircaloy-2 fuel cladding tubes under biaxial stress, Journal of Nuclear Science and Technology 12 (7) (1975) 423-435.

[20] T. Andersson, A. Wilson, Ductility of Zircaloy canning tubes in relation to stress ratio in biaxial testing, in: J. Schemel, T. Papazoglou (Eds.), 4th International Symposium on Zirconium in the Nuclear Industry, ASTM STP681, 1979, pp. 60-71. 
[21] E. Kaplar, L. Yegorova, K. Lioutov, A. Konobeyev, A. Jouravkova, V. Smirnov, A. Goryachev, V. Prokhorov, O. Makarov, S. Yeremin, A. Svyatkin, Mechanical properties of unirradiated and irradiated Zr$1 \mathrm{Nb}$ cladding : Procedures and results of low temperature biaxial burst tests and axial tensile tests, Tech. Rep. NUREG/IA-0199, U.S. Nuclear regulatory Comission (2001).

[22] A. Hellouin de Menibus, Q. Auzoux, J. Besson, J. Crepin, Hydride blisters formation, characterization and effect on the fracture of zircaloy-4 cladding tubes under reactivity initiated accident conditions, in: Light Water Reactor Fuel Performance Meeting, American Nuclear Society, Charlotte, North Carolina, USA, 2013.

[23] J. Desquines, D. Koss, A. Motta, B. Cazalis, M. Petit, The issue of stress state during mechanical tests to assess cladding performance during a reactivity-initiated accident (RIA), Journal of Nuclear Materials 412 (2) (2011) 250-267. 